\title{
Preliminary screening of the possible protective effect of Moroccan propolis against chromium-induced nephrotoxicity in animal model
}

\author{
Soukaina El-Guendouz (D), Soumia Zizi(i), Youssef Elamine (iD) and Badiaa Lyoussi \\ Laboratory of Physiology-Pharmacology and Environmental Health, Faculty of Sciences Dhar-Mahraz, University Sidi \\ Mohamed Ben Abdellah, Fez, Morocco. \\ Corresponding author: Badiaa Lyoussi, e-mail: lyoussi@gmail.com \\ Co-authors: SE: soukaina.elguendouz@gmail.com, SZ: ziziepaissaoui@gmail.com, YE: elamineysef@gmail.com \\ Received: 12-11-2019, Accepted: 19-05-2020, Published online: 14-07-2020
}

doi: www.doi.org/10.14202/vetworld.2020.1327-1333 How to cite this article: EL-Guendouz S, Zizi S, Elamine Y, Lyoussi B (2020) Preliminary screening of the possible protective effect of Moroccan propolis against chromiuminduced nephrotoxicity in animal model, Veterinary World, 13(7): 1327-1333.

\begin{abstract}
Background and Aim: Hexavalent chromium (Cr (VI)) compounds have been shown to induce nephrotoxicity associated with oxidative stress in humans and animals. The aim of the present study was to investigate the nephroprotective effect of bee propolis, as highly antioxidant natural product, in vivo using an animal model.

Materials and Methods: First of all, total phenol and flavonoid contents of propolis sample were estimated in vitro. Afterward, to study the protective effect of propolis on renal damages caused by an injection of a single dose of potassium dichromate ( $15 \mathrm{mg} / \mathrm{kg} \mathrm{b.wt),} 24$ male Wister rats were divided into test and control groups. Propolis treatment was performed by oral gavage of $100 \mathrm{mg} / \mathrm{kg} \mathrm{b.wt/day,} \mathrm{while} \mathrm{the} \mathrm{control} \mathrm{groups} \mathrm{received} \mathrm{water} \mathrm{instead.} \mathrm{The} 24 \mathrm{~h}$ urine was collected and blood samples were withdrawn before and after each treatment for further analysis.

Results: Propolis revealed to be rich in polyphenols and flavonoids. Chromate provoked a nephrotoxic effect expressed by a drastic decrease in glomerular filtration assessed by creatinine clearance. However, the administration of propolis attenuated the renal damages induced by the chromate. This attenuation can be seen by the increase of creatinine clearance when comparing propolis treated group to the non-treated group.

Conclusion: Propolis showed a protective potential against chromate-induced nephrotoxicity through the amelioration of chromate's toxic effects. It might be concluded that propolis could be effective as chemoprotectant in the management of potassium dichromate-induced nephrotoxicity.
\end{abstract}

Keywords: antioxidant, chromium, phenols, propolis, renal damage.

\section{Introduction}

The biotoxic effects of many heavy metals such as arsenic, barium, cadmium, chromium $(\mathrm{Cr})$, lead, and selenium on human health are of great concern. Those metals originate from various sources comprising mining, natural weathering of the earth's crust, sewage discharge, industrial effluents, and many others. In general, exposure to those toxicants can be by ingestion, inhalation, or skin contact. Cr, a plentiful metal in the earth's crust, this dangerous element exists in the environment at different degrees of oxidation ranging from $(+2)$ to $(+6)$. However, the most common oxidation states of $\mathrm{Cr}$ are trivalent $\mathrm{Cr}^{+3}$ and hexavalent $\mathrm{Cr}^{+6}$ [1]. It was reported that both states $\left(\mathrm{Cr}^{+3}\right.$ and $\left.\mathrm{Cr}^{+6}\right)$ are toxic to humans, animals, and plants [2-4]. Naturally occurring $\mathrm{Cr}$ compounds are generally in the trivalent state, while hexavalent $\mathrm{Cr}$ compounds (the most

Copyright: El-Guendouz, et al. Open Access. This article is distributed under the terms of the Creative Commons Attribution 4.0 International License (http://creativecommons.org/licenses/ by/4.0/), which permits unrestricted use, distribution, and reproduction in any medium, provided you give appropriate credit to the original author(s) and the source, provide a link to the Creative Commons license, and indicate if changes were made. The Creative Commons Public Domain Dedication waiver (http:// creativecommons.org/publicdomain/zero/1.0/) applies to the data made available in this article, unless otherwise stated. toxic form) are mostly derived from human activities [5]. According to Jaishankar et al. [6], $\mathrm{Cr}^{+3}$ has low membrane permeability, which makes it generally innocuous comparing to $\mathrm{Cr}^{+6}$. The toxicity of this last form is more hazardous because it penetrates the cells much more easily than does the $\mathrm{Cr}^{+3}[6]$, while, $\mathrm{Cr}^{+3}$, in trace concentrations, is essential for regular operation of human vascular and metabolic systems as well as combating diabetes in trace. Contrariwise $\mathrm{Cr}^{+6}$ may cause health problems including allergic reactions, skin rash, nose irritations and nosebleed, ulcers, immune system deterioration, genetic material alteration, and kidney and liver damage and may even go as far as death of the individual $[7,8]$.

Moreover, $\mathrm{Cr}$ exposure has been associated with kidney diseases, according to the urinary data, these kidney toxicants seem to target mainly the proximal tubular cells leading to oxidative stress, endoplasmic reticulum stress, and mitochondrial damages resulting in apoptosis and necrosis $[7,8]$. On the other hand, nowadays, natural products provide an excellent strategy toward identifying new bioactive compounds for combating a large number of human diseases, especially those induced by oxidative stress. Propolis is a resinous substance collected by honeybees from parts of plants, buds, and exudates and mixed with bees wax and salivary enzymes. It is mostly constituted 
by resin, wax, essential oils, and pollen. Its richness in bioactive polyphenols makes it in a suitable natural product for the present contribution. The chemical variability found in propolis can be attributed to the geographical location, collection site, botanical origin, bee species, and the climate $[9,10]$. Different studies have shown that propolis has a broad spectrum of biological properties, such as antimicrobial, anti-inflammatory, antioxidant, antidiabetic, spasmolytic, anesthetic, anticancer, and immunomodulatory effects [9-15].

To the best of our knowledge, the protective effect of propolis against $\mathrm{K}_{2} \mathrm{Cr}_{2} \mathrm{O}_{7}$-induced nephrotoxicity has not been explored. The aim of this work was to investigate whether using propolis as a natural product, can prevent or improve the effects of $\mathrm{Cr}$-induced nephrotoxicity in an animal model.

\section{Materials and Methods}

\section{Ethical approval}

The ethical approval was obtained from Sidi Mohamed Ben Abdellah University in Fez, under the responsibility of the Animal Facility and the Laboratory of Physiology-Pharmacology and Environmental Health, Faculty of Sciences Dhar EL Mahraz of Fez, Morocco (USMBA-PPSE 2016-05). The care and handling of the animals were in accordance with the internationally accepted standard guidelines for the Care and Use of Laboratory Animals, and the protocol was approved by our institutional committee on animal care, University Sidi Mohamed Ben Abdellah, Faculty of Sciences Dhar EL Mahraz Fez, Morocco. All efforts were made to minimize animal suffering and the number of animals used.

\section{Study period and location}

The experiment was conducted at the Laboratory of Physiology-Pharmacology and Environmental Health, Faculty of Sciences Dhar EL Mahraz Fez, Morocco, during March to May 2017.

\section{Sample preparation}

Propolis sample was obtained from a beekeeper's association in Fez, Morocco. Ten milliliters of distilled water were added to $100 \mathrm{mg}$ of propolis powder for total phenols and flavonoids determination. Regarding the in vivo experiment, distilled water was added to obtain the required propolis concentration which was orally administered to the animals for 10 days.

\section{Determination of phenolic groups}

\section{Total phenol content}

The total polyphenol content in propolis sample was determined using the method of El-Guendouz et al. [10]. Propolis $(25 \mu \mathrm{L})$ was mixed with $125 \mu \mathrm{L}$ of Folin-Ciocalteu reagent $(0.2 \mathrm{~N})$ and $100 \mu \mathrm{L}$ of $7.5 \%$ $\mathrm{Na}_{2} \mathrm{CO}_{3}$, and the absorbance was measured at $760 \mathrm{~nm}$ after $2 \mathrm{~h}$ of incubation at room temperature. The total polyphenol content was expressed as milligrams of ferulic acid equivalents per milliliter (mg FAE/mL) using a calibration curve.

\section{Total flavones/flavonols content}

The amount of flavones and flavonols in the propolis was determined according to the method of El-Guendouz et al. [10]. Briefly, $100 \mu \mathrm{L}$ of $\mathrm{Al}_{2} \mathrm{Cl}_{3}$ (20\%) were added to $100 \mu \mathrm{L}$ of extract, and after $1 \mathrm{~h}$ of incubation at room temperature, the absorbance was recorded at $420 \mathrm{~nm}$. Total flavone and the flavonol contents were calculated as quercetin equivalents per milliliter ( $\mathrm{mg} \mathrm{QE} / \mathrm{mL}$ ) using a calibration curve.

\section{Total flavanones and dihydroflavonol contents}

The quantification of total flavanone and dihydroflavonol compounds was performed according to El-Guendouz et al. [10], where $75 \mu \mathrm{L}$ of sample or standard (Eriodictyol) and $2 \mathrm{~mL}$ of 2,4-dinitrophenylhydrazine (DNP) solution (1 g DNP in $2 \mathrm{~mL} \mathrm{96 \%}$ sulfuric acid, diluted to $100 \mathrm{~mL}$ with methanol) were mixed and heated at $50^{\circ} \mathrm{C}$ for $50 \mathrm{~min}$. After cooling at room temperature, the mixture was diluted to $10 \mathrm{~mL}$ with methanolic $\mathrm{KOH}$ solution $(10 \%$, w/v); then, 1 $\mathrm{mL}$ of the resulting solution was diluted to $50 \mathrm{~mL}$ with methanol and the absorbance was measured at $486 \mathrm{~nm}$.

\section{Experimental animals}

Adult male Wistar rat's weighing $190 \pm 20 \mathrm{~g}$ were obtained from our Animal House Breeding Center, Department of Biology, Faculty of Sciences Dhar El Mahrez Fez, Morocco. The animals were housed under standard environmental conditions $\left(25 \pm 2^{\circ} \mathrm{C}\right.$, $55 \pm 5 \%$ humidity and $12 \mathrm{~h} / 12 \mathrm{~h}$ light/dark cycle) and allowed free access to tap water and standard laboratory rat chow.

\section{Experimental design}

The rats were divided into four groups of six rats each, as follows:

Group I: Served as healthy control and received distilled water $(10 \mathrm{~mL} / \mathrm{kg} \mathrm{b.wt} /$ day $)$

Group II: Served as healthy group treated with propolis $(100 \mathrm{mg} / \mathrm{kg} \mathrm{b.wt} /$ day $)$

Group III: Rats of this group received distilled water $(10 \mathrm{~mL} / \mathrm{kg} \mathrm{b.wt} /$ day) and were injected with potassium dichromate $(15 \mathrm{mg} / \mathrm{kg}$ b.wt/single dose)

Group IV: Received propolis (100 mg/kg b.wt/day) and were injected with $15 \mathrm{mg} / \mathrm{kg}$ b.wt of potassium dichromate.

The animals were kept in metabolic cages, experimentation was continued for 10 days, and the animals received the treatments daily. Potassium dichromate aqueous solution was administered by subcutaneous injection of single dose at day 4 of the experiment and propolis was given by oral gavage daily.

\section{Biological mediums sampling and analysis}

The $24 \mathrm{~h}$ urine samples were collected in graduated cylinders, to determine the urine volume for each rat, filtered, centrifuged, and stored at $-20^{\circ} \mathrm{C}$ until the day of analysis. Blood samples were withdrawn at the 
beginning, before starting the experimental protocol, and after 10 days, centrifuged at 4000 r.p.m for 10 min, and then, the plasma was collected and stored at $-20^{\circ} \mathrm{C}$ until analysis.

Plasma and urine electrolytes concentration, glucose, triglycerides, and cholesterol profiles were measured by flame spectrophotometry. Concentration of creatinine in plasma and urine was determined by the Jaffe alkaline picrate method, and creatinine concentration was measured by spectrophotometer at 500 $\mathrm{nm}$. Creatinine clearance was used to evaluate the renal function, or more exactly, the glomerular filtration rate, and was calculated from plasma and urinary creatinine levels following the formula:

$\left(\right.$ Creatinine $_{\text {Urine }} /$ Creatinine $\left._{\text {Serum }}\right) \times\left(\right.$ Volume $_{\text {Urine }}$ $(\mathrm{mL}) /$ Time $(\mathrm{h}) \times 60)$

\section{Statistical analysis}

All data were analyzed using GraphPad Prism 5 (GraphPad Software, La Jolla, CA, USA) and the results were expressed as mean \pm standard deviation. Within group, means comparison was performed through the analysis of variance test. A significant difference between the control and experimental groups was assessed using student's t-test. $\mathrm{p}<0.05$ was considered to be statistically significant.

\section{Results}

\section{Phenols}

The concentrations of total phenols, flavones and flavonols, and flavanones and dihydroflavonols found in propolis samples used in this work are displayed in Figure-1. Propolis showed a high amount of phenolic compounds with a value of $6.21 \pm 0.02 \mathrm{mg}$ $\mathrm{FAE} / \mathrm{mL}$. Regarding the flavones and flavonols content, it was high as $3.91 \pm 0.20 \mathrm{mg} \mathrm{QE} / \mathrm{mL}$, while the amount of flavanones and dihydroflavonols amount was $2.31 \pm 0.01 \mathrm{mg} \mathrm{QE} / \mathrm{mL}$ in the studied propolis sample (Figure-1).

\section{Nephrotoxicity induction and chemoprotective effect of propolis}

\section{Urinary volume}

In the present work, we evaluate the effect of propolis on alleviating the chromate-induced nephrotoxicity in Wister rats after single subcutaneous dose injection. The results displayed in Figure-2, show that

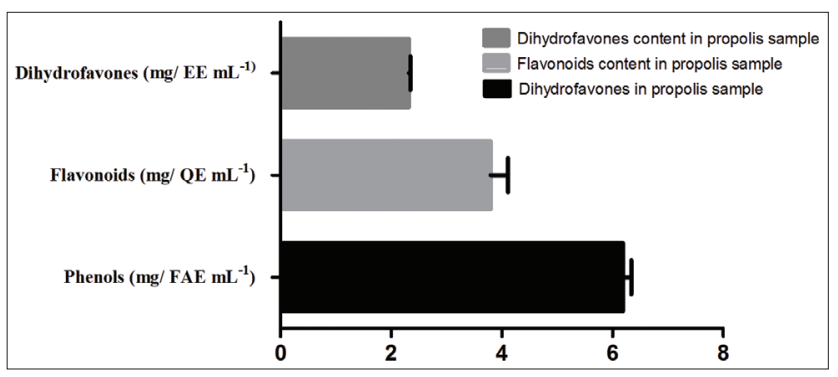

Figure-1: Concentration of total phenols, flavonols, flavones, flavanones, and dihydroflavonols in propolis sample. the urinary volume increases significantly $(\mathrm{p}<0.001)$ in the $5^{\text {th }}$ day $(8.01 \pm 0.12 \mathrm{~mL} ; 7.76 \pm 0.15 \mathrm{~mL})$ and $6^{\text {th }}$ day $(7.92 \pm 0.12 \mathrm{~mL} ; 7.85 \pm 0.15 \mathrm{~mL})$ for the none treated nephrotoxic group and for that injected with dichromate and treated with propolis, respectively, as compared to the healthy control group. Afterward, for the none treated nephrotoxic animals, a significant decrease $(p<0.001)$ of the urine volume was observed starting from day $7(2.22 \pm 0.25 \mathrm{~mL})$ until the end of the experiment $(0.12 \pm 0.10 \mathrm{~mL})$. Regarding the nephrotoxic group treated with propolis, a significant decrease $(p<0.001)$ of the diuresis on day $7(1.05 \pm 0.38 \mathrm{~mL})$ was observed. However, this diuresis starts recovering the normal volume on day 8 . It is worth mentioning that the administration of propolis to healthy rats did not affect their $24 \mathrm{~h}$ urinary volumes (Figure-2).

\section{Electrolytes levels and creatinine clearance}

The effects of the interventions with propolis along with/without $\mathrm{Cr}$ on urinary and plasma sodium and potassium are summarized in Table- 1 . The results showed that significant changes can be seen in some electrolytes following $\mathrm{Cr}$ injection. While, no significant changes in unary $\mathrm{Na}^{+}$and $\mathrm{K}^{+}$were induced for the healthy group treated with propolis, as compared with control made of healthy animals. Cr injection in the absence of any treatment induced a significant decrease $(p<0.001)$ of both parameters (Table-1). However, propolis supplementation attenuated the decrease observed following $\mathrm{Cr}$ injection.

Regarding the plasma electrolyte $\mathrm{Na}^{+}$, both nephrotoxic groups revealed a significant difference $(p<0.05)$ as compared to the control healthy group. While, the plasmatic $\mathrm{K}^{+}$has significantly increased $(\mathrm{p}<0.001)$ in the none treated nephrotoxic group $(7.00 \pm 0.5 \mathrm{mmol} / \mathrm{L})$ as compared to the control $(3.1 \pm 0.81 \mathrm{mmol} / \mathrm{L})($ Table-1). However, propolis treatment maintained this parameter around the normal values $(4.17 \pm 0.14 \mathrm{mmol} / \mathrm{L})$.

On the other hand, according to Figure-3, the administration of propolis to healthy rats did not affect the creatinine clearance during the experiment comparing with the control. In contrast, the injection of chromate caused a drastic reduction of renal function. This reduction can be seen by the significant decrease $(p<0.001)$ of the creatinine clearance by the end of the experiment. Regarding the group supplemented with propolis, a significant alleviation against the adverse effect of Cr injection was observed (Figure-3).

\section{Osmolality and the clearance of free water}

All groups showed no significant change in plasma osmolality as compared to the control. In contrast, the injection of dichromate alone decreased significantly free water clearance which provides more evidence about the occurrence of renal function disorder as compared to control group. As for the other parameters, propolis administration restored significantly $(p<0.01)$ the renal function through maintaining these parameters in normal values (Table-2). 


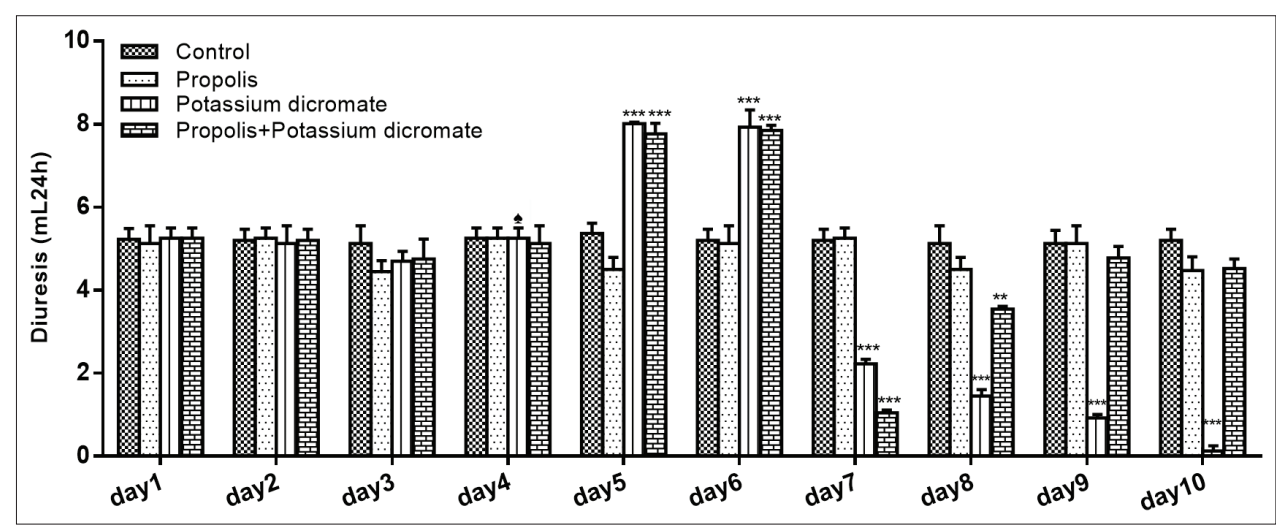

Figure-2: Average of urinary volume excretion (UV) of control and treated rats during 10 days of treatment. The volume of $24 \mathrm{~h}$ urine was measured and reported as mean \pm standard error of the mean for six rats in each group. ^ Chromium injection day.

Table-1: Concentrations of urinary and plasma electrolyte in control and treated rats after 10 days of treatment.

\begin{tabular}{|c|c|c|c|c|}
\hline \multirow[t]{2}{*}{ Groups } & \multicolumn{2}{|c|}{ Urinary electrolyte concentration } & \multicolumn{2}{|c|}{ Plasma electrolyte concentration } \\
\hline & $\mathrm{Na}^{+}(\mathrm{mmol} / \mathrm{L})$ & $\mathrm{K}^{+}(\mathrm{mmol} / \mathrm{L})$ & $\mathrm{Na}^{+}(\mathrm{mmol} / \mathrm{L})$ & $\mathrm{K}^{+}(\mathrm{mmol} / \mathrm{L})$ \\
\hline Control & $75.25 \pm 1.47$ & $54.6 \pm 0.75$ & $141.00 \pm 0.70$ & $3.1 \pm 0.81$ \\
\hline Propolis & $76.30 \pm 0.47$ & $49.25 \pm 0.24$ & $139.00 \pm 0.70$ & $3.08 \pm 0.11$ \\
\hline Potassium dichromate & $22.02 \pm 1.01 * * *$ & $7.4 \pm 0,18 * * *$ & $136.00 \pm 1.41 *$ & $7.00 \pm 0.5 * * *$ \\
\hline Propolis/potassium dichromate & $58.80 \pm 0.15^{*}$ & $35.56 \pm 0,18 *$ & $127.00 \pm 1.58 *$ & $4.17 \pm 0.14^{*}$ \\
\hline
\end{tabular}

Data are presented as mean $\pm \mathrm{SD}, * * \mathrm{p}<0.05$ compared to control, $* * \mathrm{p}<0.01$ compared to control, $* * * \mathrm{p}<0.001$ compared to control. SD: Standard deviation

Table-2: Concentrations of biochemical parameters in control and treated rats after 10 days of treatment.

\begin{tabular}{lcccc}
\hline Groups & $\mathbf{U}_{\text {osm (mosm/kgH20) }}$ & $\mathbf{P}_{\text {osm (mosm/kgH20) }}$ & $\mathbf{C}_{\text {osm }(\mathbf{\mu l} / \mathbf{m i n})}$ & $\mathbf{C}_{\mathbf{H 2 0}(\mathbf{\mu l} / \mathbf{m i n})}$ \\
\hline Control & $1580 \pm 9$ & $286 \pm 6$ & $27.62 \pm 2$ & $-22.6 \pm 2$ \\
Propolis & $1526 \pm 9$ & $278 \pm 6$ & $24.7 \pm 2.2$ & $-20.20 \pm$ \\
Potassium dichromate & $440 \pm 9 * * *$ & $227 \pm 8$ & $3.5 \pm 0.5 * * *$ & $-1.6 \pm 0.1 * * *$ \\
Propolis/potassium dichromate & $1880 \pm 9$ & $254 \pm 6$ & $14.4 \pm 1.2 * *$ & $-11.30 \pm * *$ \\
\hline
\end{tabular}

Data are presented as mean $\pm \mathrm{SD}, * * \mathrm{p}<0.05$ compared to control, $* * \mathrm{p}<0.01$ compared to control, $* * * \mathrm{p}<0.001$ compared
to control. SD: Standard deviation

\section{Blood glucose, triglycerides, cholesterol levels, and creatinine clearance}

The results of biochemical parameters showed that the dichromate leads to a significant increase in blood glucose concentrations, triglycerides, and cholesterol levels ( $<<0.001 ; p<0.001$; and $p<0.01$, respectively). The values of those parameters increased from $1.15 \pm 0.14 \mathrm{~g} / \mathrm{L}, 0.95 \pm 0.22 \mathrm{~g} / \mathrm{L}$, and $0.47 \pm 0.08 \mathrm{~g} / \mathrm{L}$ in normal rats to $2.78 \pm 0.10 \mathrm{~g} / \mathrm{L}, 1.34 \pm 0.03 \mathrm{~g} / \mathrm{L}$, and $1.23 \pm 0.01 \mathrm{~g} / \mathrm{L}$, respectively, in nephrotoxic individuals. The supplementation with propolis moderated the acute effect of chromate on the mentioned parameters and the values were $1.81 \pm 0.16 \mathrm{~g} / \mathrm{L}, 1.02 \pm 0.02 \mathrm{~g} / \mathrm{L}$, and $0.61 \pm 0.12 \mathrm{~g} / \mathrm{L}$, respectively (Table-3).

\section{Discussion}

Heavy metals toxicity in organism, including that of $\mathrm{Cr}$, was associated with the generation of reactive oxygen species (ROS), leading to an oxidative stress [16]. Cr is well-known as oxidizing agent able to induce tissue damages directly. The humans and animals' exposure to $\mathrm{Cr}^{6+}$ compounds induce carcinogenic, mutagenic, and teratogenic effects $[6,17]$.
Many studies showed that oral feeding of $\mathrm{Cr}$ leads to a significant increase in organosomatic indices of liver, kidneys, heart, and spleen [18]. Balakrishnan et al. [7] reported that the administration of $\mathrm{Cr}$ to rats significantly reduced the antioxidant markers of kidney such as superoxide dismutase and glutathione (GSH). Moreover, it increased the peroxidation markers such as malondialdehyde. Furthermore, Velma and Tchounwou [16] found that the kidney appears to be more vulnerable and sensitive to Cr-induced toxicity than the liver.

In this context, some authors found that $\mathrm{Cr}$ chelating agents or antioxidants such as $\alpha$-tocopherol, ascorbic acid, and GSH can ameliorate $\mathrm{Cr}$-induced oxidative damage by scavenging the ROS and/or preventing biological macromolecules from oxidative injury [19-21]. Kandhare et al. [22] and Chetyrkin et al. [23] reported that L-arginine and pyridoxamine, which have antioxidant properties, significantly restored alteration in serum and urine biochemical parameters.

Several authors have shown that propolis exhibited a strong antioxidant property [9,12,24-27]. 
Table-3: Effects of oral administration of propolis, potassium dichromate, propolis/potassium dichromate, and distilled water on various parameters measured (mean $\pm S D$ ).

\begin{tabular}{lccc}
\hline Groups & Glucose $(\mathbf{g} / \mathbf{L})$ & Triglycerides $(\mathbf{g} / \mathbf{L})$ & Cholesterol $(\mathbf{g} / \mathbf{L})$ \\
\hline Control & & & \\
Propolis & $1.15 \pm 0.14$ & $0.95 \pm 0.22$ & $0.47 \pm 0.08$ \\
Potassium dichromate & $0.85 \pm 0.12^{* *}$ & $0.75 \pm 0.11$ & $0.51 \pm 0.05$ \\
Propolis/potassium dichromate & $2.78 \pm 0.10^{* * *}$ & $1.34 \pm 0.03^{* * *}$ & $1.23 \pm 0.01^{* *}$ \\
\hline
\end{tabular}

$* * \mathrm{p}<0.05$ compared to control, $* * \mathrm{p}<0.01$ compared to control, $* * * \mathrm{p}<0.001$ compared to control. SD: Standard deviation

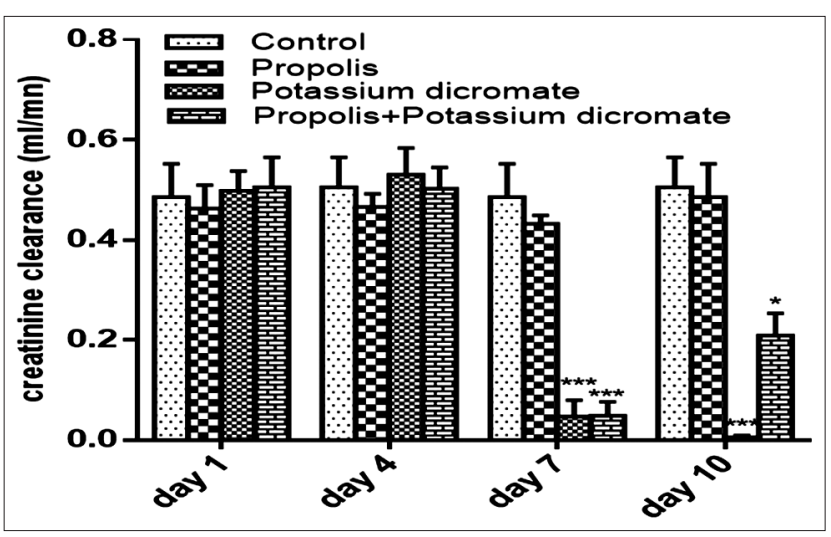

Figure-3: Effect of propolis and potassium dichromate on creatinine clearance in normal Wistar rats treated and control. Data are presented as mean \pm standard deviation, $* * p<0.05$ compared to control, $* * p<0.01$ compared to control, $* * * p<0.001$ compared to control.

This activity was attributed to some of its bioactive compounds. In general, phenolic compounds and flavonoids have been found to be the major components of propolis, and they were reported to be the responsible of its antiradical activity [9,12,26-28]. In concordance with those authors, El-Guendouz et al. [10] and Miguel et al. [12] have found that propolis samples with higher concentrations of phenolic compounds exhibit a higher antioxidant power and anti-inflammatory properties.

In this study, total phenol contents found in the propolis sample are within the range of those generally detected in methanolic extract of Portuguese propolis, 2.93-8.76 $\mathrm{mg}$ pinocembrin equivalent $/ \mathrm{mL}$ and 1.28-2.76 mg QE/mL, for total phenol and flavonoid contents, respectively [29]. Our results are in concordance with those reported for Moroccan ones, which were ranging between 0.039 and $8.864 \mathrm{mg}$ FAE $/ \mathrm{mL}$ for phenols, 0.020 and $4.320 \mathrm{mg} \mathrm{QE} / \mathrm{mL}$ extract for the flavonoids, and 0.031 and $0.532 \mathrm{mg}$ $\mathrm{EE} / \mathrm{mL}$ extract for dihydroflavones [10]. Even in the absence of a deep histological study to evaluate the kidney damage caused by $\mathrm{K}_{2} \mathrm{Cr}_{2} \mathrm{O}_{7}$, it was evident to state the occurrence of renal function disorder given the severe decrease of the urinary volume and an acute increase of urinary and plasma electrolyte $\mathrm{Na}^{+}$and $\mathrm{K}^{+}$, blood glucose, triglycerides, and cholesterol levels following dichromate intervention. Furthermore, a significant change in creatinine clearance, osmolality, and clearance of free water was recorded as a result of this Cr toxicity. While, after the pretreatment of rats with propolis before the $\mathrm{Cr}$ injection, it was observed a significative acceleration in the recovery of the previously mentioned affected parameters. In parallel, we found that chronic administration of propolis did not affect urinary volume of rats.

In sum, injection of chromate decreased the urinary output, and the glomerular filtration rate assessed by creatinine clearance as compared with the control rats. This effect can be explained by the fact that the glomerular filtration rate decreased due to the obstruction of urinary outflow. Besides, the obstruction of the urinary outflow leads to an accumulation of waste products in the blood including sodium and potassium. Those observations were proved by our results and explain the death of nephrotoxic animals by the end of the experiment. The levels of the electrolytes $\mathrm{Na}^{+}$and $\mathrm{K}^{+}$decreased in urine and increased in plasma for chromate injected group, while, the group of animals pretreated with propolis showed a lower increment of the electrolyte levels in urine. This finding suggests that propolis exerted a protective effect on renal damage as it alleviates the $\mathrm{Cr}$ effect. In this regard, we have found that propolis extract increased creatinine clearance until restoration of renal function. Many studies focused on the protective role of the antioxidant effect of propolis against the toxicity of several heavy metals. Wen et al. [30] reported a possible protective effect of propolis against aluminum-induced toxicity, while Masry et al. [31] demonstrated the same effect but against lead-induced neurotoxicity. Other researchers [32] showed the positive influence of the administration of propolis on reducing the concentration of mercury in the muscles, kidneys, and liver in animal models. In a previous study [33], our group of research has reported that this propolis sample exhibits great potential as an antioxidant agent after the in vitro evaluation of its ability for scavenging free radicals, azino-bis3-ethylbenzothiazoline-6-sulfonic acid, and nitric oxide and by their reducing power. Hence, we can attribute the found effect in this work to this bioactive property of propolis.

On the whole, our current results showed that propolis has been useful in preventing kidney damage caused by dichromate, suggesting that this nephroprotective effect was through its antioxidant and ROS scavenging properties through the action of flavonoids and phenolic compounds it contains. 


\section{Conclusion}

$\mathrm{Cr}$ injection in rats caused kidney failure and it was alleviated by propolis intervention. Propolis protected against functional alterations of the kidney. The phenolic compounds were possibly involved in its beneficial effect.

From above, we speculate that propolis by virtue of its renoprotective property ameliorates potassium dichromate-induced loss of functional integrity in kidney tissues. On the basis of this study, it should be taken into consideration that the supplementation of natural antioxidants such as propolis may act as a protective agent against the toxicity of chromates and, therefore, could be a significant intervention for future testing in kidney failure. Those results will be with a high interest and can be with a potential clinical application. However, there is a clear need to characterize the quality and quantity of the constituents of propolis and to identify the mechanism of action to confirm the present results.

\section{Authors' Contributions}

BL: Conceptualization and supervision. SE, YE, and SZ: Methodology, laboratory experiments, and biochemical analysis. SE: manuscript writing. YE and BL: Review of the draft. All authors read and approved the final manuscript.

\section{Acknowledgments}

This work was supported by University Sidi Mohamed Ben Abdallah, Morocco with a grant, USMBAL10 PPSE. The authors want to thank Laboratory of Physiology, Pharmacology and Environmental Health, Faculty of Sciences Dhar El Mahraz, Morocco, for providing the facilities to carry out the research work.

\section{Competing Interests}

The authors declare that they have no competing interests.

\section{Publisher's Note}

Veterinary World remains neutral with regard to jurisdictional claims in published institutional affiliation.

\section{References}

1. Haq, Z., Jain, R.K., Khan, N., Dar, M.Y., Ali, S., Gupta, M. and Varun, T.K. (2016) Recent advances in role of chromium and its antioxidant combinations in poultry nutrition: A review. Vet. World, 9(12): 1392-1399.

2. Hamidi, O., Mohammad, C., Hasan, G., Ali, A. Hassan, M. (2017) Effects of chromium (III) picolinate and chromium (III) picolinate nanoparticles supplementation on growth performance, organs weight and immune function in cyclic heat stressed broiler chickens. Arch Vet Sci, 2017: AVST-113.

3. Liu, C.S. Kuo, H.W., Lai, J.S. and Lin, T.I. (1998) Urinary $\mathrm{N}$-acetyl-betaglucosaminidase as an indicator of renal dysfunction in electroplating workers. Int. Arch. Occp. Environ. Health, 71(5): 348-352.

4. Mohanty, M. and Patra, H.K. (2013) Effect of ionic and chelate assisted hexavalent chromium on mung bean seedlings (Vigna radiata 1 . Wilczek. Var k-851) during seedling growth. J. Stress. Physiol. Biochem., 9(2): 232-241.

5. Agency for Toxic Substances and Disease Registry. (2012) Chromium Toxicological Profile, US Department of Health and Human Services, Agency for Toxic Substances and Disease Registry, Atlanta, GA.

6. Jaishankar, M., Mathew, B.B., Shah, M.S. and Gowda, K.R.S. (2014) Biosorption of few heavy metal ions using agricultural wastes. Int. J. Environ. Res. Public Health, 2(1): 1-6.

7. Balakrishnan, R., Satish K.C.S., Rani, M.U., Srikanth, M.K., Boobalan, G. and Reddy, A.G. (2013) An evaluation of the protective role of $\alpha$-tocopherol on free radical induced hepatotoxicity and nephrotoxicity due to chromium in rats. Indian. J. Pharmacol., 45(5): 490-495.

8. Hong, S., Jason, B. and Max, C. (2015) Oral chromium exposure and toxicity. Curr. Environ. Health Rep., 2(3): 295-303.

9. Miguel, M.G., Nunes, S., Dandlen., S.A., Cavaco, A.M. and Antunes, M.D. (2010) Phenols and antioxidant activities of hydro-alcoholic extracts of propolis from Algarve, South of Portugal. Food Chem. Toxicol., 48(12): 3418-3423.

10. El-Guendouz, S., Aazza, S., Lyoussi, B., Antunes, M.D., Faleiro, M.L. and Miguel, M.G. (2016) Antiacetylcholinesterase, antidiabetic, anti-inflammatory, antityrosinase and antixanthine oxidase activities of Moroccan propolis. Int. J. Food Sci. Tech., 51(8): 1762-1773.

11. El-Guendouz, S,. Lyoussi, B. and Miguel, M.G.C. (2019) Insight on propolis from Mediterranean countries: Chemical composition, biological activities and application fields. Chem. Biodiv., 16(7): e1900094.

12. Miguel, M.G., Doughmi, O., Aazza, S., Antunes, D. and Lyoussi, B. (2014) Antioxidant, anti-inflammatory and acetylcholinesterase inhibitory activities of propolis from different regions of Morocco. Food Sci. Biotechnol., 23(2): 313-322.

13. El-Guendouz, S., Aazza, S., Lyoussi, B., Bankova, V., Lourenço, J.P., Costa, A.M.R., Mariano, J.F., Miguel, M.G. and Faleiro, M.L. (2016) Impact of biohybrid magnetite nanoparticles and Moroccan propolis on adherence of methicillin-resistant strains of Staphylococcus aureus. Molecules, 21(9): 1208.

14. Sforcin, J.M. (2016) Biological properties and therapeutic applications of propolis. Phytother. Res., 30(6): 894-905.

15. El-Guendouz, S., Aazza, S., Lyoussi, B., Majdoub, N., Bankova, V., Popova, M., Raposo, S., Antunes, D. and Miguel, M.G. (2018) Effect of poplar-type propolis on oxidative stability and rheological properties of $\mathrm{O} / \mathrm{W}$ emulsions. Saudi Pharm. J., 26(8): 1073-1082.

16. Velma, V. and Tchounwou, P.B. (2013) Oxidative stress and DNA damage induced by chromium in liver and kidney of goldfish, Carassius auratus. Biomark. Insights, 25(8): 43-51

17. Thomas, L.D.M. and Max, C. (2019) Mechanisms of chromium-induced toxicity. Curr. Opin. Toxicol., 14(4): 1-7.

18. Geetha, S., Ram, M.S., Mongia, S.S., Singh, V., Ilavazhagan, G. and Sawhney, R.C. (2003) Evaluation of antioxidant activity of leaf extract of seabuckthorn (Hippophae rhamnoides L.) on chromium (VI) induced oxidative stress in albino rats. $J$. Ethnopharmacol., 87(2-3): 247-251.

19. Arreola-Mendoza, L., Reyes, J.L., Melendez, E., Martin, D., Namorado, M.C., Sanchez, E. and Del Razo, L.M. (2006) Alpha-tocopherol protects against the renal damage caused by potassium dichromate. Toxicology, 218(2-3): 237-246.

20. Park, H.K., Jeong, B.C., Sung, M., Park, M.Y., Choi, E.Y., Kim, B.S., Kim, H.H. and Kim, I.I. (2007) Reduction of oxidative stress in cultured renal tubular cells and preventive effects on renal stone formation by the bioflavonoid quercetin. J. Urol., 179(4): 1620-1626.

21. Bijarnia, R.K., Kaur, T., Aggarwal, K. and Tandon, C. (2008) Modulatory effects of $\mathrm{N}$-acetylcysteine on hyperoxaluric 
manifestations in rat kidney. Food Chem. Toxicol., 46(6): 2274-2278.

22. Kandhare, A.D., Patil, M.V. and Bodhankar, S.L. (2015) L-Arginine attenuates the ethylene glycol induced urolithiasis in nephrectomized hypertensive rats: Role of KIM-1, NGAL, and Nos. Ren. Fail., 37(4): 709-721.

23. Chetyrkin, S.V., Kim, D., Belmont, J.M., Scheinman, J.I., Hudson, B.G. and Voziyan, P.A. (2005) Pyridoxamine lowers kidney crystals in experimental hyperoxaluria: A potential therapy for primary hyperoxaluria. Kidney Int., 67(1): 53-60.

24. Betances-Salcedo, E., Revilla, I., Vivar-Quintana, A.M. and González-Martín, M.I. (2017) Flavonoid and antioxidant capacity of propolis prediction using near infrared spectroscopy. Sensors, 17(7): E1647.

25. Piccinelli, A.L., Mencherini, T., Celano, R., Mouhoubi, Z., Tamendjari, A., Aquino, R. and Rastrelli, L. (2013) Chemical composition and antioxidant activity of Algerian propolis. J. Agric. Food. Chem., 61(47): 5080-5088.

26. Osés, S.M., Pascual-Maté, A., López-Diaz, M.A., LópezDiaz, T.M. and Sancho, M.T. (2016) Bioactive properties of honey with propolis. Food. Chem., 196(4): 1215-1223.

27. Revilla, I., Vivar-Quintana, A.M., González-Martín, I., Escuredo, O. and Seijo, C. (2017) The potential of near infrared spectroscopy for determining the phenolic, antioxidant, color and bactericide characteristics of raw propolis. Microchem. J., 134(3): 211-217.
28. Magdalena, W., Lucyna, M., Agnieszka, W., Tomasz, R. and Izabela, R. (2019), The role of seasonality on the chemical composition, antioxidant activity and cytotoxicity of polish propolis in human erythrocytes. Rev. Bras. Farmacogn., 29(3): 301-308.

29. Miguel, M.G., Nunes, S., Dandlen, S.A., Cavaco, A.M. and Antunes, M.D. (2014) Phenols, flavonoids and antioxidant activity of aqueous and methanolic extracts of propolis (Apis mellifera L.) from Algarve, South Portugal. J. Food. Sci. Technol., 34(1): 16-23.

30. Wen, Y.F., Zhao, J.Q., Nirala, S. and Bhadauria, M. (2012) Aluminum-induced toxicity and its response to combined treatment of HEDTA and propolis in rats. Pol. J. Environ. Stud., 21(5): 1437-1444.

31. Masry, T.A., Emara, A.M. and Shitany, N.A. (2011) Possible protective effect of propolis against lead induced neurotoxicity in animal model. J. Evol. Biol. Res., 3(1): 4-11.

32. Jose, L., Valverde, P., Agata, Z., Hussein B.K., Sylwia, E.S. and Ewa, R. (2018) Influence of the administration of propolis and bee pollen preparation on the concentration of mercury in the muscles, kidneys and liver of white storks. Med. Weter., 74(3): 171-174.

33. El-Guendouz, S., Al-Waili, N., Aazza, S., Elamine, Y., Zizi, S., Al-Waili, T., Al-Waili, A. and Lyoussi, B. (2017) Antioxidant and diuretic activity of co-administration of Capparis spinosa honey and propolis in comparison to furosemide. Asian Pac. J. Trop. Biomed., 10(10): 974-980. 